\title{
Information Connectivity as A Primary Instrument to Enhance Transport Connectivity
}

\author{
Setyo Nugroho ${ }^{*}$, Muhammad Badrus Zaman ${ }^{2}$, Murdjito $^{3}$, Eko Budi Djatmiko ${ }^{4}$, Wolfgang Busse ${ }^{5}$
}

\begin{abstract}
A case study on Maratua to enhance the quality of life is perceived to be achieved through the enhancement of the transport connectivity. The physical connectivity is manifested in the form of transport connectivity, entails the availability and the ease of obtaining a transport service to transfer goods and people. Deeper efforts to understand the mechanism of obtaining a transport service entails a primary actor directing both the ship and cargoes or passengers. This actor is the information connectivity. The paper elaborates promising efforts towards managing the information connectivity as a key for enhancing the transport service.
\end{abstract}

Keywords — information connectivity, transport connectivity, remote islands.

I. INTRODUCTION

$\mathrm{S}$ mall islands often entail two paradoxes, natural beauties and challenges. Indonesia with its 17.504 islands, 17.475 of them are small islands with an area less than 200 sq.km. Three thousand of the islands are inhabited.

Transportation services nearly all aspects of life in small islands, from the supply of goods, education, healthcare, energy till tourism. Transportation in small islands faces huge challenges, as the economy scale is low, it does not adequately attract investors to put high quality services in those areas.

Sustainable Island Development Initiatives (SIDI), established in 2012, aims to address a wide range of aspects related to the well-being of the people of small islands in a sustainable way. The Digital Island Transport (DI-Transport), aims to improve the transport systems of its adopted islands by mainly, but not limited to, digital solutions. As a pilot project, focus is directed to maritime transport system of one particular island, Maratua, which is one of the 92 outermost islands of Indonesia that is renowned as a popular diving destination, figure 1. The success of Digital Island ideas could theoretically serve as an important stepping stone to address similar problems in many small islands in Indonesia, South East Asia or Pacific.

Setyo Nugroho, Department of Sea Transportation, Institut Teknologi Sepuluh Nopember, Surabaya 60111, Indonesia, Email: snugroho@na.its.ac.id

Muhammad Badrus Zaman, Department of Marine Engineering, Institut Teknologi Sepuluh Nopember, Surabaya 60111, Indonesia, Email: drus_zaman@yahoo.com

Murdjito, Department of Ocean Engineering, Institut Teknologi Sepuluh Nopember, Surabaya 60111, Indonesia, Email: murdjito@oe.its.ac.id

Eko Budi Djatmiko, Department of Ocean Engineering, Institut Teknologi Sepuluh Nopember, Surabaya 60111, Indonesia, Email: ebdjatmiko@oe.its.ac.id

Wolfgang Busse, Hochschule Wismar, Germany. Email: wolfgang.busse@hs-wismar.de
II. METHOD

\section{II.1 Transportation Challenge}

In the case of Maratua, there are 25 boats serve the transport from Maratua to Tanjung Redeb vice versa. The availability of ships does not entirely reflect the frequency of service. People still are not always easy to obtain a boat from Maratua to Tanjug Redeb v.v. in table 1 .

In average our of 25 boats, 3 boats depart daily to form Maratua to Tanjung Redeb vv.v. Even the route is fixed, the departure time seems to have a character of tramp shipping. When the boat is over $50 \%$ occupied, then the boat is willing to depart. Delays are not an usual case.

Another source of delay is weather. Weather conditions are relatively smooth. Speedboats used in service travel with a speed of 25-30 knots. With this speeds, the trip between Tanjung Redeb and Maratua can be accomplished in 3,5-4 hours i friendly weather. The boats operate between 06:00-17:00, in table 2 .

Preference of users weighing between tariff, departure time and level of comfort investigation provides valuable information, in figure 2. This information serves a foundation to design the proposed solution, and its new business process.

\section{2 Information Connectivity}

It used to be hard in 2012 to make a phone call on any small island, including Maratua. Steadily, the ease of phone conversation grows. We witness a growing information connectivity in the past five years. Today there are more and more people using smartphones. More kids use either a smartphone or a tablet, though this number is far below the national level. over $70 \%$ of internet users live on Java. Some $85 \%$ of people access internet through smartphone, $32 \%$ through laptop, 14 and $13 \%$ through PC and tablet respectively.

This is in line with the global trend, where the usage of mobile computing, tablet or smartphone, grows faster, overtaking that of personal computers.

This fact is an important consideration for addressing the soft infrastructure to address challenges in small islands, even though today's state of information 
International Journal of Marine Engineering Innovation and Research, Vol. 2(2), Mar. $2018.98-101$ (pISSN: 2541-5972, eISSN: 2548-1479)

connectivity is far lower than in better developed areas, such as in Berau or Balikpapan.

The accessibility of people on small islands to smartphone is growing, users could find shops to top-up their smartphone more and more easily. Apart form it, electricity is not widely available. The internet speed is lower than average on Java, but it is adequate to access many light apps. The download speed is 2,3 Mbps, upload 0.59 MBps.

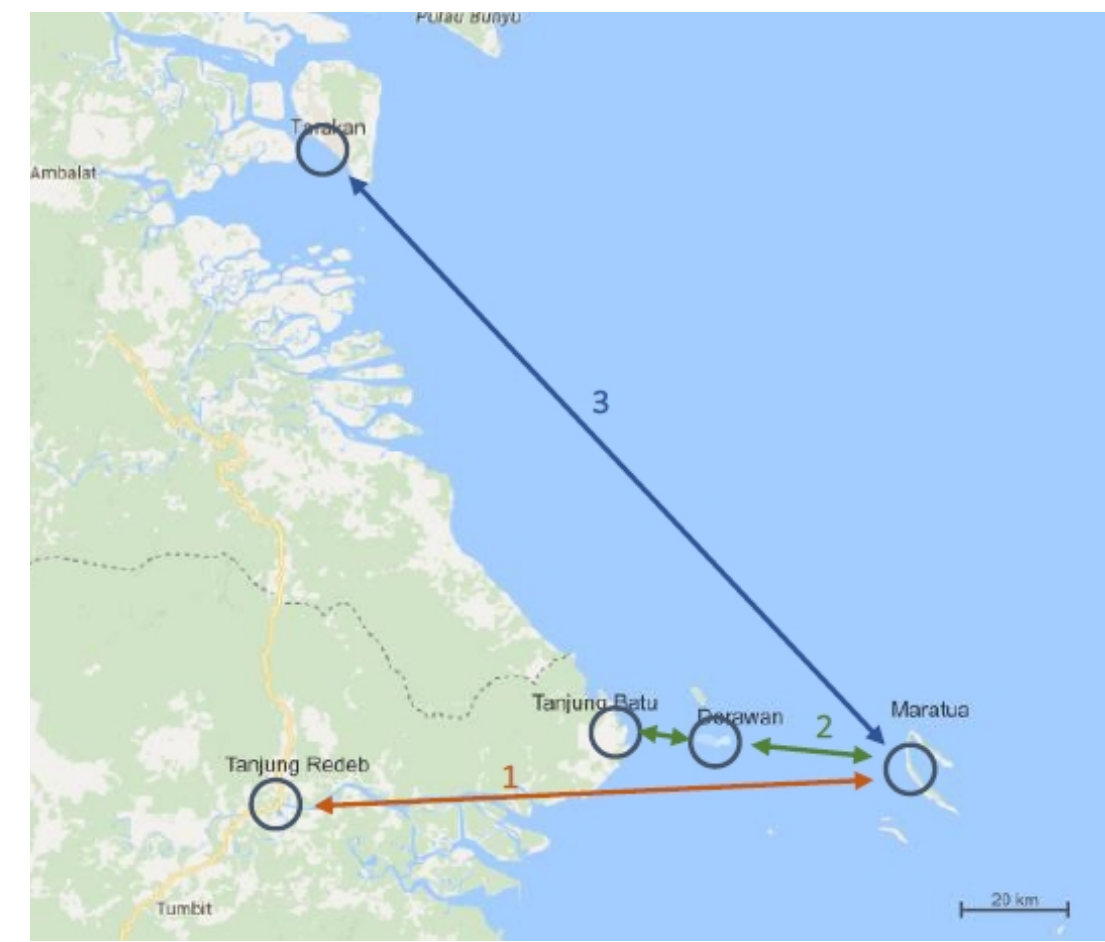

Figure. 1. Routes from and to Maratua Island

TABLE 1.

Fleet

\begin{tabular}{|c|c|c|c|c|c|c|c|c|}
\hline \multicolumn{9}{|c|}{ Fleet } \\
\hline \multirow{3}{*}{ Village } & \multicolumn{7}{|c|}{ Type of ship* } & \multirow{3}{*}{ Total } \\
\hline & \multicolumn{4}{|c|}{20 pax capacity } & \multicolumn{3}{|c|}{12 pax capacity } & \\
\hline & $250 \times 1$ & $200 \times 1$ & $115 \times 2$ & $85 \times 2$ & $115 \times 1$ & $85 \times 1$ & $40 \times 2$ & \\
\hline Teluk Harapan & 1 & 5 & 1 & 1 & 1 & 2 & 8 & 19 \\
\hline Payung-payung & & 2 & & & & & 2 & 4 \\
\hline Bohe Silian & & & & & & & & 2 \\
\hline
\end{tabular}

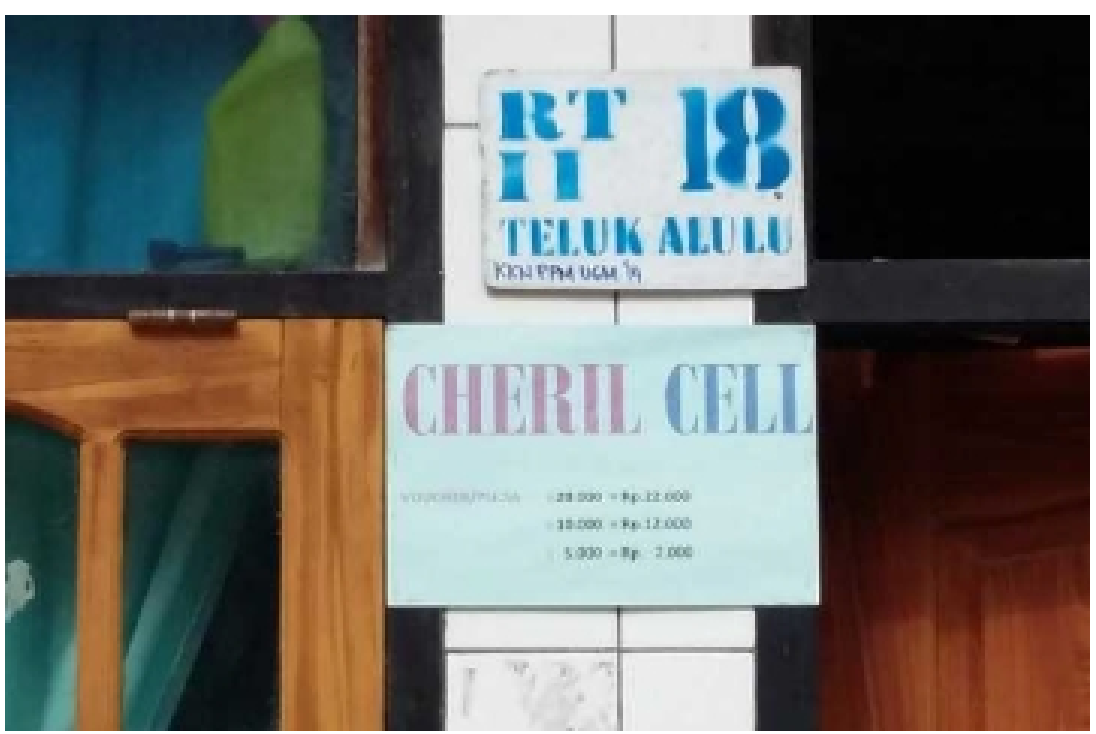

Figure. 2. Topping-up facility for smartphone users 
International Journal of Marine Engineering Innovation and Research, Vol. 2(2), Mar. $2018.98-101$ (pISSN: 2541-5972, eISSN: 2548-1479)

TABLE 2.

Tariff vs departure time vs comfort: a survey (Alafi, 2017)

\begin{tabular}{|c|c|c|c|}
\hline 1 & Boat 1 & Boat 2 & Boat 3 \\
\hline Departure & afternoon & tomorrow morning & this morning \\
\hline Tariff (Rp) & 200.000 & 650.000 & 950.000 \\
\hline Comfort & $*$ & $* *$ & $* * *$ \\
\hline 2 & Boat 1 & Boat 2 & Boat 3 \\
\hline Departure & afternoon & this morning & tomorrow morning \\
\hline Tariff (Rp) & 500.000 & 950.000 & 350.000 \\
\hline Comfort & $* * *$ & $*$ & $* *$ \\
\hline 3 & Boat 1 & Boat 2 & Boat 3 \\
\hline Departure & this morning & afternoon & tomorrow morning \\
\hline Tariff (Rp) & 950.000 & 350.000 & 200.000 \\
\hline Comfort & $*$ & $* * *$ & $* *$ \\
\hline 4 & Boat 1 & Boat 2 & Boat 3 \\
\hline Departure & tomorrow morning & afternoon & this morning \\
\hline Tariff (Rp) & 350.000 & 800.000 & 500.000 \\
\hline Comfort & $* *$ & $* * *$ & $*$ \\
\hline 5 & Boat 1 & Boat 2 & Boat 3 \\
\hline Departure & this morning & tomorrow morning & afternoon \\
\hline Tariff (Rp) & 800.000 & 500.000 & 650.000 \\
\hline Comfort & $* * *$ & $* *$ & $*$ \\
\hline 6 & Boat 1 & Boat 2 & Boat 3 \\
\hline Departure & tomorrow morning & this morning & afternoon \\
\hline Tariff (Rp) & 650.000 & 200.000 & 800.000 \\
\hline Comfort & $* *$ & $*$ & $* * *$ \\
\hline
\end{tabular}

\section{RESULTS AND DISCUSSION}

\section{III.1 Digital Island-Transport}

The smartcity is an increasingly popular concept. Many places in the world have been experimenting with this concept to adopt information and communication technology to assist citizens to better benefit from nearly any kind of services provided locally, through mobile apps or websites. Empirically, it is reported to have a success rate of some $25 \%$.

Nevertheless, this efforts seem to be unstoppable. The potential of addressing citizen's challenges seems to be huge, still. Many transportation services do not satisfy people, not because of lack of vehicles, or lack of services. The survey on the processes of booking a boat, shows that, the delays or cancellations are often caused by lack of information on the transport services. Boat owners do not inform adequately to candidate passengers on the schedule updates. When users reach the berth in order to depart, the boat has gone, see in figure 3 .

Meanwhile, there are many boats are berthed, empty. If over someone is ready to charter it or a group of over 10 people are there, that boat could be departed anytime. A classical approach to determine the fleet size or the infrastructure dimensions is therefore not applicable at all.

The spread of updated information on ships's departure an the information integrity are the key of the problem. This drives the boat users and owners to decide, taking a certain boat or another, a cheaper or a more comfortable, now or few hours later.

Learning from the success of various mobile app for city transport, the Digital Island - Transport idea is to facilitate users to:

1. Receive information on availability of transport services of the day.

2. Select a desirable boat, considering the departure time, price and comfort.

3. Book a seat.

The spread of updated information on ships's departure an the information integrity are the key of the problem. This provides a room for the boat users and owners to decide, taking a certain boat or another, a cheaper or a more comfortable, for now or for few hours later. Spreading reliable transport information would give transport users access to service, they could rely upon. This would minimize delays and cancellations. Spreading information to wider public better guarantees for accumulating more potential passengers. Having this system in place. a better transport system could be achieved, by improving transport connectivity. 


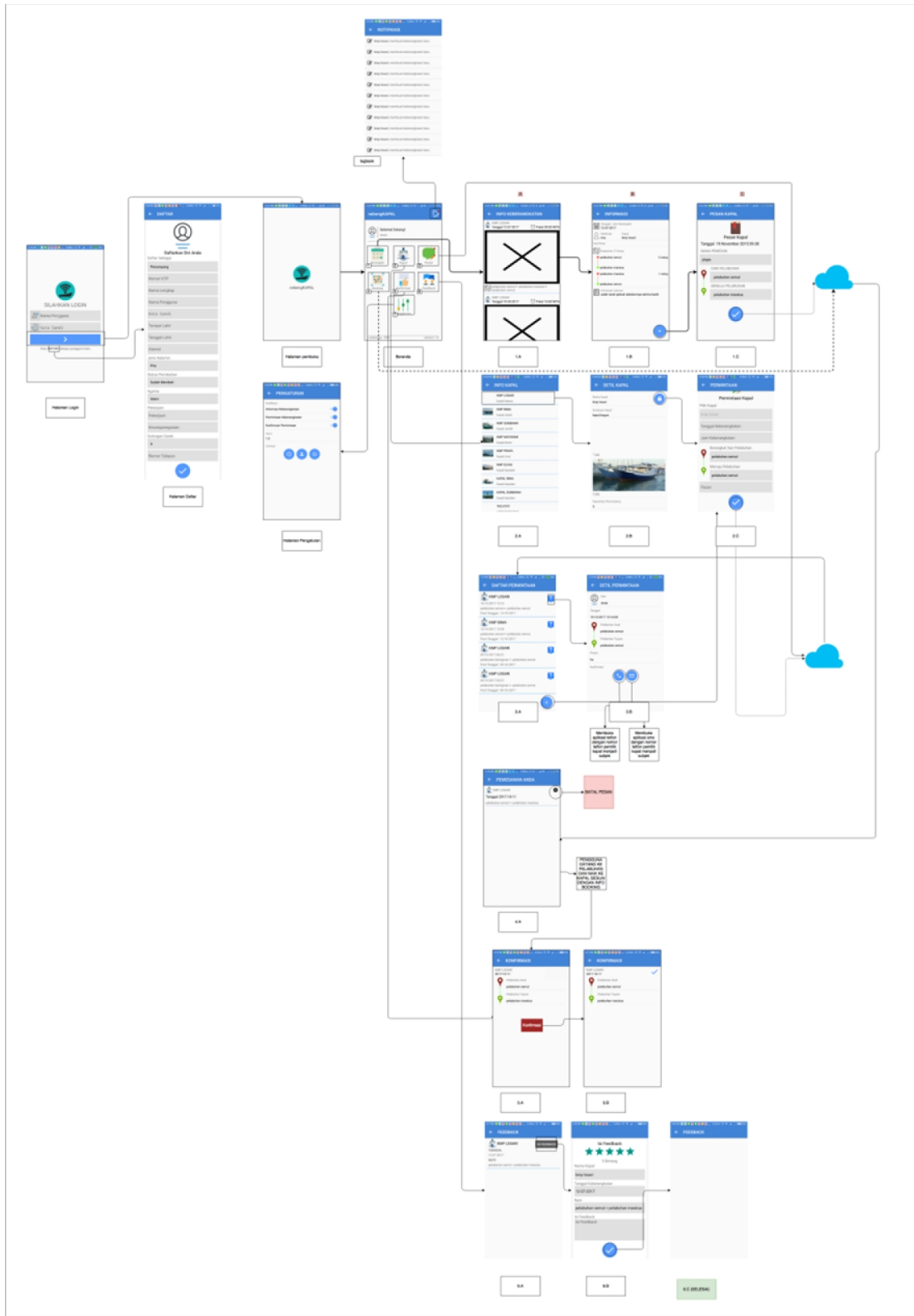

Figure. 3. Booking process using the app

\section{CONCLUSION}

This study explores the development of digital education in Maratua Island. From the discussion, can taken the conclusion:

1. Challenges of transportation in small islands is mainly not the availability of hard infrastructure such as berth or terminal facilities, nor the lack of hard suprastructure such as ships. It is the availability of transport services. To be more specific, it is the lack of regular and affordable transport service.

2. An important reason for the above challenge is the small scale of economy of the island. Small islands are of low population density. Many cancellations and delays are attributed to lack of updated transport information.

3. An approach to address the above is to improve information connectivity by providing a transport information service, to ensure the sailing schedules, and to increase reliability of transport service. A prototype of a mobile solution has been established. manuscript must be make a conclusion from this research in the end of manuscript. Conclusion is made based on the research results or finding

\section{REFERENCES}

[1] Gudmundsson, H, et.al., (2016) Sustainable Transportation. Springer H. K., Desai, K. P. \& Raval, H. K.

[2] Nijikamp, P., Pepping, G., Banister., D., (2016). Telematics and Transport Behaviour. Springer

[3] McQueen, B., Judy McQueen, J.,(1999).Intelligent Transportation Systems Architectures. Artech House Boston.

[4] Weintrit, A., Neumann, T.,. (2011)Transport Systems and Processes. CRC Press Taylor and Francis Group.

[5] Alafi, J. (2017) Evaluating and Improving the Maritime Transport Services of Small Islands of Indonesia: A Choice Behaviour Study, MSc Thesis, TU Delft, 2017. 